\title{
Correction to: Does Test Anxiety Predispose Poor School-Related Wellbeing and Enhanced Risk of Emotional Disorders?
}

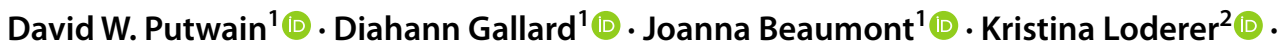 \\ Nathaniel P. von der Embse ${ }^{3}$ (])
}

Published online: 9 April 2021

○) Springer Science+Business Media, LLC, part of Springer Nature 2021

\section{Correction to: Cognitive Therapy and Research https://doi.org/10.1007/s10608-021-10211-x}

The original version of this article unfortunately contained a mistake. The reference citation "(-et al. 2020a, b)" under subheading "Test Anxiety" should read as "(Putwain et al. 2020c)". The original article has been corrected.

Publisher's Note Springer Nature remains neutral with regard to jurisdictional claims in published maps and institutional affiliations.

The original article can be found online at https://doi.org/10.1007/ s10608-021-10211-x.

David W. Putwain

D.W.Putwain@ljmu.ac.uk

1 School of Education, Liverpool John Moores University, IM Marsh Campus, Mossley Hill Rd, Liverpool L17 6BD, UK

2 Department of Psychology, University of Augsburg, Augsburg, Germany

3 University of South Florida, Tampa, USA 